Psychrometry has a history which goes back to the early part of the nineteenth century. Still a major method for measuring the humidity of air, it finds extensive applica. tion in meteorology, air conditioning, and industry. Both theoretical and experimental papers treated the use of psychrometers under such unusual conditions as temporatures below freezing and hot, arid atmospheres. Other electric hygrometric instruments that were described included those using the Peltier effect, spoctroscopic mothods, infra-red and ultra-violet radiation, and, operating in another area of the spoctrum, microwave refractometers and hygrometers.

In dew-point and frost-point hygromotors humidity is measured as the temperature at which dew or frost is dэposited on a cooled surface, usually a highly polished mirror. Theoretical aspects of this method of measurement and improved versions of dew-point and frost-point instruments were deseribed. Considerable interest was shown in hygrometers utilizing the Peltier offect to cool the mirror and others providing high accuracy with automatic operation and continuous recording.

Unusual measuring methods were also described, among them a chemical technique for measurements of low water-vapour pressure. Another paper described an instrument detecting the heat generated with water absorption by a desiccant and still others the design of cells which absorb and electrolyse water vapour for measurement of humidity as a function of the electrolysing current. Critical discussions of the advantages and shortcomings of thermal conductivity methods and hair hygrometers were presented in review papers.

\section{Moisture Measurements}

The latest advances in the art of measuring moisture in solids and liquids also had a place in the symposium, since moisture critically affects the behaviour of many materials. A session devoted to physical and chemical methods included papers describing gas chromatography, spectrophotometry, chomical extraction, and infra-red analysis. Further sessions treated dielectric, resistive and capacitance methods, as well as nuclear methods, nuclear magnetic resonance in particular. The papers described equipment, methods of calibration, and typical uses and presented data on aceuracy.

\section{Standards}

The sessions on humidity standards were of special interest to staff members of the National Bureau of Standards, several of whom presented papers on this subject, and in general to scientists needing accurate hygrometry devices. Two of the papers described for the first time the use of the gravimetric hygrometer in making humidity measurements to a degrec of accuracy suitable for the most demanding humidity calibrations. Other papers described pneumatic bridges developed at the National Bureau of Standards which make possiblo calibration-level hygrometric determinations as a function of the pressure differential across the bridge. Also of intorest in this area were papers discussing the use of fixed humidity points in hygrometer calibrations.

\section{Applications}

The sessions concerned with the application of humidity and moisture measurements included the topics of meteorology, agriculture, biology and medicine, air conditioning, humidification and de-humidification, environmental chambers and radio propagation and atmospheric refraction. In these sessions, particularly, scientists and engineers had an opportunity to learn about each other's measurement problems and to exchange information among widely separated fields and disciplines.

The part played by humidity in meteorological phenomena was covered in detail by the papers presented. The distribution of moisture in the atmosphere was discussed, and special tochniques reported for its determination in the stratosphere. A 'state-of-the-art' survey on the application of hygrometry to meteorology was also presented.

Humidity and moisture are important in agriculture in many ways. Examples discussed were storage of agricultural products, particularly grain, flour and tobacco; curing peanuts and tobacco; the physiological responses of dairy cattle to humidity; the moisture content of butter, dehydrated foods and dry milk; and the moisture content of soils and its influence on plant growth.

The session on biology and medicine included papers on the effects of humidity on man, plants and biological systems. Humidity affects personal comfort, and imposes a stress on those working in hot environments; when controlled it can be used in treating lung disorders, for example.

The papers presented concerning air-conditioning, humidity control, humidification, and de-humidification were of a highly practical and engineering nature. Typical of the problems discussed were air-conditioning calorimetry, moisture in small refrigerating systems, residential humidification, chomical de-humidification, moisture control in dry-cleaning solutions, monitoring moisture in sealed electronic modules, and humidity levels in environmental cabinets and chambers.

Propagation of radio signals, observations of missile trajectories, and monitoring atmospheric turbulence depend to a largo extent on the refractive index of the atmosphere which, in turn, is a function of the ambient vapour pressure. Rescarch in this area also was presented. A paper on the potential of radio refractometry for humidity investigations and one on the use of radio refractometers to measure water vapour turbulence were presented. Papers on the use of radio, optical and microwave techniques for humidity measurements also were delivered.

The papers presented at the symposium will be published by the Reinhold Publishing Corp., New York, and are expected to bccome available early next year.

\title{
REPROCESSING FOR IRRADIATED FUELS
}

A SYMPOSIUM on "Aqueous Reprocessing Chemistry for Irradiated Fuels" was held in Brussels during April 23-26, under the auspices of the European Nuclear Energy Agency of the Organization for European Cooperation and Development and of the European Company for Chemical Proccssing of Irradiated Fuels (Eurochemic).

The object of the conference was to compare the progress made by the European countries which participate in Eurochemic, with the status of work in the samo field in the United States and the United Kingdom. About half the twenty papers presented were concerned with research and devolopment work being carried out either at Mol, Belgium, or elsewhere in Europe for the Eurochemic plant which is under eonstruction at Mol. Other papers from French and Italian authors were related to possible new reprocessing plants in theso two countries. As descriptions have been published in recent years on the major reprocessing plants of the United States and the United Kingdom, contributions from these countries were largely limited to surveys of recent developments.

It is apparent that on the Continent, as elsewhere, a solution of tributylphosphate in a hydrocarbon diluent is 
regarded as the most reliable solvent extraction system for the recovery of uranium and plutonium from irradiated fuels. The degree to which this system is capable of technical improvement is now largely limited to ways in which the effluents of moderate radioactivity can be reduced in volume, for example, by using only one cycle, or be made capable of being evaporated to small bulk: in papers concerned with the latter aim, the results of research on the substitution of ferrous sulphamate by uranium (IV) nitrate as the reducing agent for the reaction plutonium (IV) $\rightarrow$ plutonium (III) were described. Otherwise, as was brought out in the contribution by Dr. $R$. Rometsch, the research director of Eurochemic, the main load that now falls on a research and development team is concerned with the problems involved in 'decladding' the wide variety of fuel elements used in Western European reactors and in bringing their contained fuel into solution of such a composition as to be suitable for the recovery of the fissile elements by solvent extraction.

There is now little work being done on ion exchangers for reprocessing: in the period 1950-60 they were developed and sometimes installed for the final purification of plutonium and uranium-233. The present tendency is to establish for these purification steps a solvent extraction process using a tertiary (or quaternary) amine, in a suitable organic diluent. The results from several laboratories on amine systems indicate that sufficient knowledge has already been accumulated for an amine-cycle to be capable of being successfully applied for this purpose. The two advantages of an amine, compared with the conventional tributylphosphate, for this particular purification-cycle consists in the better decontamination from uranium, and the greater reduction in the volume of the plutonium nitrate stream that the amine can provide.

Although the symposium dealt mainly with aqueous methods, there was a review by Dr. M. D'Hont (Nuclear Energy Centre, Mol, Belgium) on the alternatives, for example, reprocessing by melt refining or by fractional volatilization from halide systems. It is noticeable that these and similar non-aqueous methods, though a popular field for research at the time of the Geneva Conferences of 1955 and 1958, are losing favour. Their development costs seem likely to be prohibitive for any purpose other than an established fuel-cycle operating on a large number of reactors.
The final session was devoted to a discussion on the future role of reprocessing in fuel-cycles. It was introduced by Dr. F. L. Culler (Oak Ridge National Laboratory), who quoted his investigation on a scheme for the distillative purification of sea-water using, as a source of power, very large reactors (each of 8,700-MW thermal) fuelled with natural uranium, and cooled and moderated with heavy water: the lowness of the reprocessing cost (calculated to be about 4 dollars/kg of uranium) for the fuel-cycle concerned was primarily due to its large throughput (about 10 tons of uranium per day). This illustrated the important point that the throughput of a plant can influence costs to a greater degree than possible savings from improved technology. In the discussion which followed, two points of particular interest emerged. First, in the early stages of the expansion of the nuclear reactor industry, storage of irradiated fuels until such time as adequate quantities have accumulated to feed a large reprocessing plant may be preferable, on economic grounds, to the proliferation of many small plants: it would follow as a corollary of this policy, that the number of teams engaged on reprocessing research and development that should support such reprocessing would be relatively few in number. Secondly, for large reprocessing plants to be generally accepted, the problems in the transport of irradiated fuel both by water and on land must be overcome: these problems can be particularly severe where international boundaries have to be crossed.

About 100 persons drawn from fifteen countries as well as from the International Atomic Energy Agency and from Euratom attended the symposium, in addition to the forty scientists and technologists from Eurochemic. The meeting provided the first large gathering of the reprocessing experts of Western Europe and it was appropriate that the delegates could see at Mol the emergence of the Eurochemic plant. Dr. T. J. Barendregt and the others responsible under Dr. E. Pohland, the director-general of Eurochemic, for this plant have had to overcome many problems, new in plant construction, due to the components being supplied by one or other of the various countries which participate in Eurochemic. The plant represents a pioneering effort, new in Europe, from which benefits should accrue to many future co-operative enterprises.

J. M. Fletcher

\section{FLOW STUDY OF POLYMER MELTS USING THE INSTRON RHEOMETER}

\begin{abstract}
A $\mathrm{T}$ the meeting of the Cambridge Rheology Club held on March 4, Mr. G. G. Zahler (Instron, Ltd.) spoke on "Flow Study of Polymer Melts using the Instron Rheometer". First, he briefly discussed general flowcharacteristics of polymer melts showing that temperature, speed of flow and stress measurement should be accurately controlled, instrument geometry must be accurate and accessible. A rheometer must cover shear rates from at least 1 to 10,000 reciprocal seconds in order to simulate normal processing conditions from compression moulding to injection moulding.

The Instron rheometer, which is an extrusion type and was originally designed by Monsanto Chemicals (United States), is driven by an Instron model $T T$ - $C$ tensile testing machine. This machine covers load ranges from $2 \mathrm{~g}$ to $10,000 \mathrm{lb}$., using strain-gauge load cells, to an accuracy of 0.5 per cent on all ranges. Speeds are governed by a synchronous motor and positional servo-system, being instantly selectable through pushbuttons over a range of 10,000 to 1 .
\end{abstract}

The extrusion assembly consists of a barrel surrounded by four heaters connected to a controller giving proportional, integral and differential control from $10^{\circ} \mathrm{C}$ above ambient to $340^{\circ} \mathrm{C}$ within a limit of error of $\pm 0.5^{\circ} \mathrm{C}$. Capillaries of different diameters, lengths and entrance angles are inserted into the lower end of the barrel. A plunger is forced through the barrel by the moving crosshead of the tensile testing machine, the load on the plunger is recorded automatically by the load cell on a strip chart recorder. Tests over wide ranges of speed may be earried with one barrel loading. As plunger speed is known, plunger load is measured and dimensions of the extrusion assembly have been accurately determined, shear rate and shear stress can be readily calculated or read directly from nomo. graphs.

Mr. Zahler discussed possible errors such as due to the capillary aspect ratio, plunger friction force, fluid compressibility and temperature rise along the capillary, etc. $\mathrm{He}$ showed that all these effects were either negligible or could be easily corrected.

It was suggested that it is possible to measure the dynamic shear modulus (for visco-elastic flow) by steadystate flow in the capillary rheometer. This theory was substantiated by results obtained experimentally. Another parameter that can be measured is the activation 